rosion Science at the Royal Institute of Technology. He forsees problems arising from the radioactivity of the waste, which would cause the release of oxygen from the water surrounding it. The resulting oxidising environment would not only favour the spread of plutonium but would also oxidise the pyrites in the bedrock into sulphuric acid, making the water extremely corrosive.

Professor Wranglen is doubtful whether any man-made material could withstand such corrosion for thousands of years, but says that, if the waste must be buried, it should be encapsulated in fire-proof steel with a coating of gold about one-tenth of a millimetre thick: thick enough to ensure absolute impenetrability. To avoid the enormous expense of such a method, he suggests that high-level radioactive waste should not be buried at all, but should be stored under supervision in concrete bunkers or drained rock chambers above the ground water table. The heat from the waste would keep the steel cylinders hot and dry for centuries, and they would need no encapsulation at all. $\mathrm{He}$ argues that resistance to this solution is purely psychological: acceptance of nuclear reactors themselves implies acceptance that the fuel and waste within them might be used in wars or other catastrophes, and we ought therefore to accept a similar risk in connection with stored waste.

In the face of all these uncertainties, it is hardly surprising that gas as an energy source has become attractive. One of Sweden's ship-building companies, Kockums, recently presented a plan in which the need for nuclear power could be reduced from an estimated ten reactors to six by 1985 if liquified natural gas (LNG) were imported from Arab countries. By 1985, gas would provide $26 \%$ of the country's energy needs; dependence on oil would stand at $37 \%$ instead of the $47 \%$ now expected, and nuclear power would provide $11 \%$ instead of an expected $29 \%$.

After the announcement of this proposal, a Swedish-American team, which has been doing research into ways of stopping leaks from underground gas storage chambers, declared that a large ship fully loaded with LNG would have an energy equivalent of a tactical nuclear weapon, and questioned the wisdom of letting such a potential disaster into the Baltic.

Looking further ahead, Sweden may be able to import natural gas from Norway through a pipeline off the projected Norway-Denmark-West Germany line whose parameters are being discussed in Oslo. According to the Norwegians' calculations, gas production would have to be 20 billion cubic metres a year to make the pipeline pay. Present production is only half of this and Norway's Prime Minister, Odvar Nordli, is reported to have refused to guess in which decade the project could begin. All of this can provide only cold comfort for Fälldin: he needs solutions right now.

Last week, $\mathrm{Mr}$ Alexei Kosygin, the Soviet Premier, opened Finland's first nuclear power station--a $440 \mathrm{MW}$ pressurised water reactor-in Loviisa, a small town south of Helsinki. The order for the power station was placed with the Soviet Union in 1970 at a value of $£ 25$ million at the then rate of exchange.

\title{
PAKISTAN
}

\section{Bones of contention}

Azim Kidwai looks at the place of science in the recent elections in Pakistan

AfTER an exceptionally emotional and at times hurtful election campaign, the ruling Pakistan People's Party led by Mr Zulfiqar Ali Bhutto swept the polls in the elections held for the National Assembly and the Provincial Assemblies on 7 and 10 March respectively. The main opposition, the Pakistan National Alliance, has challenged the results and has refused to accept them on the grounds that the elections were rigged. It boycotted the provincial elections of 10 March saying that the National Assembly elections had been unfair.

Without going into the polemics of the political scene, and accepting that the People's Party is to govern the country for the next five years, certain projections can be made on the emphasis which will be given to science and technology and the future shape of science policy in Pakistan. The policy kept in abeyance while everyone was preoccupied with the elections is now likely to be finalised, but the lessons learned from the elections might distort it to a certain extent; the first priority, one would expect, would be geared to meeting the practical needs of Pakistan as reflected during the campaign.

Science policy as such was not an election issue, and was not accorded any status as a separate issue in the manifesto of either of the major parties. The consequences of scientific and technological advance were nevertheless bones of contention. For example, the unprecedented price-spiralling during the past four years-an almost $100 \%$ rise-was the chief subject of debate in almost all election meetings. The National Alliance promised to slash prices by good management, by coming down heavily on the blackmarket and so on, and some of its leaders said they would bring them down to 1970-71 levels. The people's Party refuted the claim, saying that inflation was a complex international phenomenon and that a developing country, weak in basic science and mainly producing raw materials, had to pay through the nose for finished goods.

According to its manifesto, the People's Party is committed to making Pakistan self-sufficient in grain and oil within the next five years, and to a $50 \%$ increase in GNP without neglecting industry and defence. With its victory, therefore, agriculture and oil might take precedence; the polls reflected the greater popularity of the People's Party in the rural areas than in the urban centres (it lost heavily in
Karachi, the largest city in Pakistan), probably because it is likely to fund the agricultural sector handsomely.

Agricultural research and inputs like fertilisers, pesticides, new varieties of seeds, and the Irrigation, Drainage and Flood Control Council are likely to be favoured in the development effort. The importance of agriculture in Pakistan is demonstrated by the fact that in 1975-76 it contributed no less than 39,000 million rupees $(16$ rupees $=£ 1$ ) to a total gross domestic product of 119,000 million rupees. It also happens to be a source of livelihood for almost three quarters of the rural population, which makes up about $70 \%$ of the people of Pakistan.

Farm mechanisation could be another priority area. In 1975-76, some 11,000 tractors were imported-a $100 \%$ rise over the 1969-70 figure; tillers are to be imported from China and Japan. Productivity in agriculture is still growing very slowly, and is likely to gain impetus through the use of the available scientific and technological techniques.

Luckly for $\mathrm{Mr}$ Bhutto, sizeable quantities of oil were found last December at Dhodak in the north. Although the site is primarily a large gas-field, it is estimated to hold about 200 million barrels of oil which can start flowing in the next two or three years. Oil exploration and refineries are foremost on the agenda of the People's Party government. 